\title{
A promoção da saúde no contexto escolar
}

\author{
Health promotion in schools
}

\author{
Projeto Promoção da Saúde \\ Secretaria de Políticas de Saúde/MS*
}

A adoção do conceito de promoção da saúde como elemento redirecionador das políticas do Ministério da Saúde impõe a necessidade de sistematizar, em conformidade com os princípios do Sistema Único de Saúde, propostas intersetoriais que provoquem ou reforcem o desenvolvimento de ações com os mais diferentes setores.

O setor educacional, dada sua capilaridade e abrangência, é um aliado importante para a concretização de ações de promoção da saúde voltadas para o fortalecimento das capacidades dos indivíduos, para a tomada de decisões favoráveis à sua saúde e à comunidade, para a criação de ambientes saudáveis e para a consolidação de uma política intersetorial voltada para a qualidade de vida, pautada no respeito ao indivíduo e tendo como foco a construção de uma nova cultura da saúde.

É importante implementar estratégias integradas de aproximação com o sistema educacional, suas unidades de ensino e suas representações políticas, sem deixar de considerar como essencial a formação e qualificação docentes, na expectativa de que essas estratégias fomentem a adoção de hábitos de vida mais saudáveis e promovam mudanças individuais e organizacionais necessárias.

O Ministério da Saúde compreende que o período escolar é fundamental para se trabalhar saúde na perspectiva de sua promoção, desenvolvendo ações para a prevenção de doenças e para o fortalecimento dos fatores de proteção. Crianças, jovens e adultos que se encontram nas escolas vivem momentos em que os hábitos e as atitudes estão sendo criados e, dependendo da idade ou da abordagem, estão sendo revistos. Por outro lado, reconhece que, além da escola ter uma função pedagógica específica, tem uma função social e política voltada para a transformação da sociedade, relacionada ao exercício da cidadania e ao acesso às oportunidades de desenvolvimento e de aprendizagem, razões que justificam ações voltadas para a comunidade escolar para dar concretude às propostas de promoção da saúde.

No Brasil, de acordo com o Censo Escolar 2000, ${ }^{* *}$ existem 345.527 escolas no País, sendo 221.852 de ensino fundamental, ensino médio e de educação de jovens e adultos cujos estudantes encontram-se em idades privilegiadas para a formação de valores e hábitos favoráveis à saúde. Nessa rede de escolas, observase o predomínio de escolas públicas. Das 181.504 escolas do ensino fundamental, 163.368 são da rede pública de ensino. O mesmo ocorre no ensino médio das 19.456 escolas, 13.227 são públicas - e na educação de jovens e adultos - das 20.892, 18.933 são públicas. Uma ação direcionada para essa rede pública de ensino terá abrangência excepcional do ponto de vista geográfico e populacional. Somente no ano de 2000, 35.717.948 matrículas foram efetivadas no ensino fundamental, 8.192.948, no ensino médio, e 3.140.830, na educação de jovens e adultos. É um público que demanda ações educativas em saúde e merece o desenvolvimento de ações integradas e coesas para que se alcancem sucesso e impacto.

De acordo com dados da Área Técnica de Saúde do Adolescente e do Jovem da Secretaria de Políticas de Saúde do MS, mais da metade da população mundial tem menos de 25 anos de idade, sendo que, no caso brasileiro, a população entre 10 e 24 anos representa um terço da população geral, o que significa mais de 51 milhões de jovens. A situação da juventude brasileira merece atenção especial uma vez que os dados
Correspondência para/Correspondence to:

Ministério da Saúde

SEPN 511, Bloco C, Ed. BiHar IV Brasília, DF

E-mail: promocaod@saude.gov.br
*Texto de difusão técnico-científica do Ministério da Saúde.

**Fonte: Censo Escolar, do Instituto Nacional de Estudos e Pesquisas Educacionais. 
apontam para o crescimento do número de mortes decorrentes da violência, ${ }^{*}$ do aumento do desemprego, ${ }^{* *}$ da gravidez precoce, ${ }^{* * *}$ do número de casos de doenças sexualmente transmissíveis, ${ }^{* * * *}$ do envolvimento dessa população com drogas e seu tráfico. Para ter idéia do impacto da violência nesse grupo populacional, a depender da região, mais de $70 \%$ desses jovens morrem vítimas de causas externas (homicídio, agressão, acidente de trânsito e suicídio), e o número desses jovens que já teve algum tipo de relação com drogas e, por essa razão, encontra-se em algum tipo de medida socioeducativa é expressivo.

Uma estratégia direcionada para essa população que pretenda ter alcance significativo precisa estar associada à escola, onde grande parte dela se encontra.

A assinatura de Portaria Interministerial 766/GM, de 17 de maio de 2001, para elaboração dos Parâmetros Curriculares Nacionais em Ação - temas transversais Saúde e Orientação Sexual, estabelece o pacto entre o Ministério da Saúde e o Ministério da Educação, passo importante na implementação de uma ação integrada que terá, de início, o alcance de 2.779 municípios que já aderiram ao Programa Parâmetros Curriculares Nacionais em Ação. O programa***** conta com uma Rede Nacional de Formadores composta de 167 consultores contratados, que atuam nos 301 pólos de formação constituídos. Os números que expressam a abrangência da execução do programa apontam para 20.815 coordenadores de grupos e para 384.109 professores distribuídos em todo o território nacional.

Nessa estratégia de ação intersetorial, estão sendo agregadas instâncias políticas de ambos os setores - saúde e educação - para a elaboração, execução e avaliação de iniciativa conjunta (Conselho Nacional de Secretários Estaduais de Educação, da União Nacional dos Secretários Municipais de Educação, do Conselho Nacional de Secretários Estaduais de Saúde, do Conselho Nacional de Secretários Municipais de Saúde) e da Organização Pan-Americana de Saúde no Brasil.

\section{A elaboração coletiva dos Parâmetros Curriculares} Nacionais em Ação Saúde é um marco e a concretização de que se possa pensar a educação e a saúde sob uma ótica mais integradora. Elaborar os parâmetros e participar na formação continuada dos professores é construir uma nova cultura, em que a educação e a saúde tenham sentidos e significados mais integrais e que resultem em projetos de vidas mais saudáveis.

Os processos educativos têm como eixos a construção de vidas mais saudáveis e a criação de ambientes favoráveis à saúde, o que significa entender a educação como processo que trata o conhecimento como algo que é construído e apropriado e não como algo a ser transmitido. Conhecimento, por sua vez, é fruto da interação e cooperação entre sujeitos que são diferentes, que trazem experiências, interesses, desejos, motivações, valores e crenças que são únicas, singulares, mas que são, ao mesmo tempo, plurais, e, por isso, diversas. Um conhecimento que é incompleto e histórico.

No entanto, a educação e a saúde, como campos de conhecimentos e de práticas, têm sido consideradas a partir de suas especificidades, em que a educação está associada à escola e aos processos de aprendizagem e a saúde é identificada com os serviços de saúde e processos de adoecimento.

Vista de forma ampliada, a relação entre saúde e educação pode estabelecer a intersecção para a integração dos saberes acumulados por tais campos, uma vez que os processos educativos e os de saúde e doença incluem tanto conscientização e autonomia quanto a necessidade de ações coletivas e de fomento à participação.

Na concepção de saúde individual, seria necessário refletir sobre a saúde dos professores, seja individual ou coletivamente. $\mathrm{O}$ estresse diário dos docentes, o esforço repetitivo que o cotidiano exige, o enfrentamento de situações dramáticas não fazem parte do cotidiano escolar Uma escola promotora de saúde inclui essa idéia de saúde, de estar saudável incluindo o bem-estar docente.

Para se promover saúde não é suficiente informar. É necessário uma relação dialogal, uma comunicação emancipadora, em que os sujeitos sejam envolvidos na ação educativa, formativa e criativa, levando em conta a reconstrução do saber da escola e a formação continuada dos docentes. Promover saúde implica e requer ter paz, educação, alimentação, renda, ecossistema saudável, recursos susten-

\footnotetext{
*De acordo com os dados do Sistema de Informações sobre Mortalidade - SIM, do Ministério da Saúde, 16.133 jovens entre 10 e 19 anos morrem por causas externas. Destas, destacam-se as agressões (6.865), os acidentes de transporte (3.847), os afogamentos (1.743), os eventos indeterminados (1.515) e os suicídios (698).

**A taxa de desemprego entre jovens é superior a 13\%, enquanto a média brasileira é de 7,5\%.

*** Segundo dados do Datasus, em 1993 haviam sido feitos 2.856.255 partos, dos quais 26.505 em meninas de 10 a 14 anos e 611.608 em jovens entre 15 e 19 anos. Esses números aumentam significativamente com o passar dos anos, e, de acordo com a mesma fonte, em 2000, dos 2.504 .654 partos realizados, 32.486 foram de meninas entre 10 e 14 anos e 646.801 em jovens entre 15 e 19 anos.

****Segundo o Boletim Epidemiológico (Ano XIII, no 1 - Dez/99 a Jun/00), no total geral de infectados no Brasil, 24.261 estão entre os 10 e os 24 anos. Os casos de Aids nessa população já apontam para um índice de $11,7 \%$ do total dos casos para os jovens e de $16,2 \%$ para as jovens nessa faixa etária. 
táveis, justiça e eqüidade e desenvolver ações de promoção da saúde. No contexto escolar, tem a ver com respeito às possibilidades e aos limites do corpo, do intelecto e das emoções, da participação social e do estabelecimento de alianças.

A saúde e os temas transversais apontados pelos Parâmetros Curriculares Nacionais - a pluralidade cultural, a ética, a orientação sexual, a cidadania, o meio ambiente, o trabalho e o consumo - lidam com as condições concretas de sujeitos e comunidades sendo complementares e interdependentes. No cotidiano escolar, esses temas emergem em situações concretas de violência, de preconceito, nas tomadas de decisões, nas interações e na organização dos rituais e das festas, nos impasses entre pessoas e grupos, nos conteúdos dos textos e materiais de estudo e de trabalho.

O trabalho escolar lida com os valores, as crenças, os mitos e as representações que se têm sobre a própria relação do saber-fazer-ser educador e educando. Organizar e estimular situações de aprendizagem nas quais a saúde possa ser compreendida como direito de cidadania e um pressuposto ético, valorizando as ações voltadas para sua promoção, é inerente à escola. São múltiplas as faces do estar saudável ou estar doente, e, reconhecida essa complexidade, o professor lidará com as questões de saúde e de doença de maneira diferenciada.

Promover saúde é tocar nas diferentes dimensões humanas, é considerar a afetividade, a amorosidade e a capacidade criadora e a busca da felicidade como igualmente relevantes e como indissociáveis das demais dimensões. Por isso, a promoção da saúde é vivencial e é colada ao sentido de viver e aos sabe- res acumulados pela ciência e pelas tradições culturais locais e universais.

Criar momentos de debates sobre fatores desfavoráveis à saúde presentes nas realidades dos alunos e da comunidade escolar, mobilizando projetos, ações, com relação à saúde individual e coletiva, considerando a saúde sob seus diferentes aspectos, é possível quando se favorece o desencadear do desejo de conhecer e utilizar os recursos da própria localidade voltados para a promoção da saúde e para a atenção à doença. Uma rede de apoio, nas mais diferentes formas e instâncias, é fundamental para a promoção. São os conselhos de saúde, de direitos da mulher, de cidadania, de defesa da criança e do adolescente, tutelares, associações de moradores, de pescadores, de domésticas, de professores, grêmios estudantis, movimentos ligados a partidos políticos ou às igrejas e tantos outros.

Mobilizar recursos significa envolver essas redes ou setores governamentais e não-governamentais em ações institucionais no campo da saúde. Tanto para o educando quanto para o educador, o exercício de troca, de diálogo, de embates, de compartilhamento de saberes e fazeres, da crítica da realidade possibilitará a construção da autonomia, da solidariedade e da cooperação cidadã e se manifestará na redefinição dos eixos temáticos para as diferentes áreas e na eleição das abordagens e dos conteúdos. Essa mobilização de recursos, que, em um primeiro momento, tem o local como ponto de partida, vai sendo alargada e alcançando dimensões mais amplas e incorporando outras redes do município, do estado, da região, do País, do continente, tomando, na perspectiva mais global, uma dimensão planetária. 